\title{
Tracheal Obstruction after Insertion of a Self-Expanding Metal Esophageal Stent: Successful Management with an Endotracheal Tube, Steroids, and Radiotherapy
}

We report a new way of managing the airway compromise which can occur after placement of an esophageal self-expanding metal stent (SEMS) [1 - 5].

A 48-year-old man with an inoperable esophageal malignancy was referred for stenting. After dilation, with Savary-Gilliard dilators up to $12.8 \mathrm{~mm}$, the extent of the tumor was revealed to be from 20 to $30 \mathrm{~cm}$ from the incisors. A $15-\mathrm{cm}$ covered SEMS (Microvasive, Boston Scientific Corporation, Watertown, Massachusetts, USA) was deployed. The patient developed stridor 30 minutes later. Intravenous hydrocortisone $100 \mathrm{mg}$ was administered and stent removal was planned. The stridor stopped during the attempt to remove the stent, and therefore the stent was not removed. However, stridor recurred 36 hours later,. A tracheostomy was created, and bronchoscopy through the tracheostomy tube revealed tumor infiltration of the posterior wall of the trachea up to the carina, and extrinsic compression of the trachea from just beyond the tracheostomy tube for $2-3 \mathrm{~cm}$. The patient could

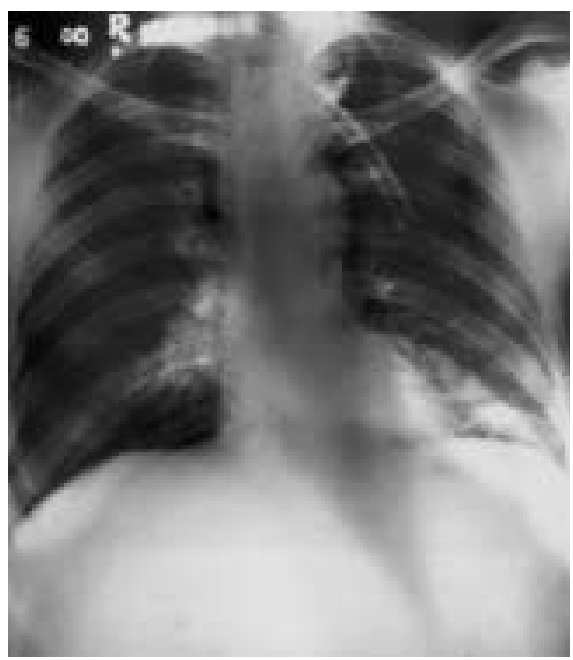

Figure 1 Chest radiograph shows the endotracheal tube which was inserted through the tracheostomy site not afford a metallic tracheal stent. The tracheostomy tube was not long enough to bypass the luminal narrowing, hence a size 7 endotracheal tube was inserted through the tracheostomy site (Figure $\mathbf{1}$ ). A short course of radiotherapy was given and hydrocortisone $100 \mathrm{mg}$ 8-hourly was continued. The following week, the endotracheal tube was removed. Bronchoscopy revealed only a $1.5-\mathrm{cm}$ ulcer on the posterior wall of the trachea with the base covered by the esophageal stent, without any residual tumor. Barium swallow did not show any leak. The tracheostomy was closed and the steroids were stopped. The patient was asymptomatic at follow-up 1 month later.

Options for managing respiratory compromise after esophageal SEMS insertion include the following: stent removal [1]; tracheobronchial stenting and/or ND:YAG laser resection of the endobronchial or tracheal tumor $[2,4,5]$; or treatment with dexamethasone with radiotherapy and continuous positive airway pressure [3]. The above facilities were not available and stent removal was impractical at 36 hours following stenting. Hence, instead we inserted an endotracheal tube through the tracheostomy to bypass the tracheal compression, and used hydrocortisone and radiotherapy to shrink the tracheal tumor, and this management was successful.

J. F. Alvares ${ }^{1}$, H. Devarbhavi ${ }^{2}$, S. Shetty ${ }^{2}$, A. Pais ${ }^{3}$, S. Sharma ${ }^{4}$

${ }^{1}$ Gastroenterology Unit 2,

St John's Medical College Hospital,

Bangalore, India

2 Department of Otolaryngology,

St John's Medical College Hospital,

Bangalore, India

${ }^{3}$ Department of Surgery,

St John's Medical College Hospital,

Bangalore, India

${ }^{4}$ Department of Radiation Medicine,

Bangalore Institute of Oncology,

Bangalore, India

\section{References}

${ }^{1}$ Libby ED, Fawaz R, Leano AM, Hassoun PM. Airway complication of expandable stents. Gastrointest Endosc 1999; 49: $136-137$

2 Dasgupta A, Jain P, Sandur S et al. Airway complications of esophageal selfexpandable metal stents. Gastrointest Endosc 1998; 47: $532-535$

${ }^{3}$ Rasiah K, Keogh G. Tracheal obstruction after insertion of a self-expanding oesophageal stent. Aust N Z J Surg 1998; 68: $77-78$

${ }^{4}$ Colt HG, Meric B, Dumon JF. Double stents for carcinoma of the esophagus invading the tracheo-bronchial tree. Gastrointest Endosc 1992; 38: $485-$ 489

${ }^{5}$ Venuta F, de Giacomo T, Rendina EA et al. Double stents for carcinoma of the esophagus invading the airway. Ann Thorac Surg 1997; 63: 1515- 1516

\section{Corresponding Author}

\section{J. F. Alvares, M.D.}

c/o Adv C. F. Alvares

Near the Holy Spirit Church

Margao-Goa 403601

India

Fax: + 91-832-420363

E-mail: afilipe@bgl.vsnl.net.in 